\title{
Development and Validation of a Community-Based Learning Resource Package in Inorganic Chemistry
}

\author{
Epiphania B. Magwilang \\ Mountain Province State Polytechnic College, \\ Bontoc, Mountain Province
}

\begin{abstract}
The chief aim of this research work was to develop and validate a learning resource package in inorganic chemistry that is community-based. The study underwent four stages of material validation, namely: preparation, development, validation and try-out. The study employed the descriptive method of research to describe and evaluate the developed learning resource package through a questionnaire checklist. Twelve chemistry experts determined the validity of the said package as to content. One hundred two chemistry students of Mountain Province State Polytechnic College determined the learning resource package's reliability as to parts specifically on objectives, content, assessment and its instructional characteristics. The resource package was further tried out on two inorganic chemistry classes employing the quasi-experimental method. Preliminary tests and post-tests were administered to the two classes to determine their performance in inorganic chemistry in terms of knowledge acquisition. Responses were tallied, tabulated and treated with appropriate statistical treatment. The study found out that the developed learning resource package was very much valid as to content and very much reliable as to parts and instructional characteristics. Further, students exposed to the developed learning resource package performed better than the students taught without the use of it. Inorganic chemistry lessons can thus be made more culturallyrelevant and meaningful to the students through the integration of community-based resources in the form of local products, everyday activities, agricultural practices, natural resources and local industries. This study therefore suggests that the developed learning resource package be adopted for use in the teaching and learning of inorganic chemistry.
\end{abstract}

Keywords: development, validation, inorganic chemistry, learning resource package, communitybased.

\section{Introduction}

Connecting lessons taught to students in school to their lives in their respective communities including tradition, indigenous works and institutions, and their local surroundings refers to community-based learning. Community-based learning is also inspired by the credence that all communities have essential, built-in resources that teachers can utilize to improve students' educational proficiencies (Hidden Curriculum, 2014). The Philippines is rich in history, literature, culture and beautiful natural environments which are possible educational resources. However, it is a common observation in Philippine schools, that what children learn is often not relevant to their day-to-day lives. Reference materials, curricula and other educational materials are highly westernized and are thus very far from the local and indigenous knowledge of the people.

Chemistry is a subject that accentuates all angles of man's endeavour and resources including food, energy, health, water, textile, paper and many more. It is the most industrially-relevant science as it has contributed much to the advancement of commerce and industry in many countries. Being the central science, chemistry also links the other natural sciences to itself and to others such as biology, astronomy, geology and physics (Brown, 1999). It is central to progress in many scientific fields. 
Chemistry however, is often viewed and experienced by students as a difficult subject. This is because chemistry has a lot of abstract concepts with its technical terms which are very difficult for students to relate to their everyday life. The teaching and learning of chemistry do not usually integrate local and community-based knowledge. This is observed in most chemistry textbooks. Textbook authors and chemistry teachers unknowingly disregard the fact that the utilization of materials which are not common to students add to their difficulty in comprehending concepts (Gabel, 1999).

In the Philippines, the most common instructional material is the textbook or reference book which is generally inadequate. As found out by UP-NISMED (2003), not enough textbooks and the lack of materials and resources to support teaching and learning are classroom realities in our country. Further, most reference books for chemistry are written by foreign authors. Foreignauthored books though, are not enough for effective teaching and learning, as core ideas of chemistry are said to be disassociated and far from the usual life experiences of learners (Braund, 1999). Students do not recognize the examples given and the substances with which they are dealing with in such books. Thus, students miss out the relation of chemistry to their surroundings and very few could really cope with chemistry works. Local instructional materials for chemistry have been developed but have not utilized nor incorporated available resources and processes in the community as examples, thus, they do not differ much from the foreign-authored books.

The use of examples which are true to life are very much recommended in chemistry teaching in the United Kingdom based on an assessment of their science program (Belt et. al., 2005). A study also indicated that the use of common materials in teaching college students have positive effects as they are more impelled to gain knowledge and skills about things connected to their lives (Phelps as cited by Gabel, 1999). In community-based learning, students are more engaged and show better understanding and attitudes towards the subject as they can visualize their lessons in their surroundings. Lessons are then easily applied when they try to solve real-world problems (CTEUW, 2019). Another research work has concluded that connecting chemistry concepts to actual life experiences, activities and environment of students result to increased achievement, positive attitudes and higher motivation levels towards chemistry (Magwilang, 2016). Indeed, performance of learners significantly improved after using localized and contextualized activities in science (Ballesteros, 2019). Localizing learning allows students to identify with the instructional material .This view is supported by the Culture-Responsive Curriculum for Indigenous People (DepEd, 2002) which emphasizes the indigenization of the country's educational programs; that learning should relate to the understanding of the indigenous settings, beliefs and principles, and the application of skills, attitudes, and values in dealing with various life situations. Further, the Department of Education, in its aim to produce Filipinos who are holistically developed with $21^{\text {st }}$ century skills has launched the $\mathrm{K}$ to 12 Philippine Basic Education Curriculum which is responsive and sensitive to culture, appropriate and all-encompassing (Ocampo, 2014).

In the Cordillera, there are many community resources which could be used as educational aids in the educational process. These include man-made and natural structures and processes such as the rivers, hot springs, rice terraces, small-scale mining processes, crude sugar preparation, wine making, indigenous food processing techniques, metal and electronic industries and the like. Students would be more interested in learning chemistry if such community resources and processes are included and used as examples in their lessons. Resources available in the community are indeed very helpful in contextualizing lessons as ideas can be encountered and observed not only in school but also at home and in the surrounding community. Using community resources and processes that are available and observable in the locality as examples in lessons gives a practical touch to theory and offers promising opportunities for the enhancement of educational applications and skills' and competencies' development. Resource materials that make conceptual abstraction more concrete and practical to the learners should be made available to students. There is a need then to develop teaching resource materials with local examples that could complement and supplement other reference books as well as assist students develop curiosity and a desire to extend their knowledge and skills. Such community-based materials will make chemistry learning friendlier and more real to the students thereby making learning more practical and less vague. Thus, the integration and utilization of local community resources and processes could be a starting point for a better chemistry instruction. 
Hence, this study of developing a learning resource package in Inorganic Chemistry with contents based on community resources is deemed necessary.

\section{Statement of the Problem}

This study aimed to develop a learning resource package which integrates community resources in Inorganic Chemistry lessons and concepts. Specifically, this study answered the following questions:

1. What community-based resources can be identified, integrated and packaged as a learning resource for Inorganic Chemistry?

2. How reliable is the community-based learning resource package (LRP) for Inorganic Chemistry as evaluated by MPSPC chemistry students?

2.1 What is the degree of correlation of the evaluation ratings of the students on the different parts and instructional characteristics of the resource package?

3. How valid are the contents of the community-based learning resource package (LRP) for Inorganic Chemistry as evaluated by chemistry experts?

4. Would the developed learning resource package (LRP) enhance students' performance in terms of knowledge acquisition?

\section{Research Design}

The descriptive method of research was utilized as it attempted to develop a Community-based LRP in Inorganic Chemistry and assess how valid and reliable it is. It involved four stages: Preparation, Development, Validation and Try-out. To determine the students' performance in inorganic chemistry in terms of knowledge acquisition, the study utilized the quasi-experimental design specifically the time series design where the comparisons between preliminary test and post-test results were done after the treatment was given to the experimental group. The time series design used is illustrated below;

Time Series Design

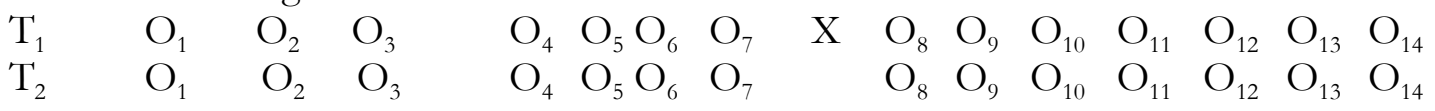

Where:

$$
\begin{aligned}
& \mathrm{X}-\text { treatment } \\
& \mathrm{O}_{1}-\mathrm{O}_{8}-\text { pre-test before every unit } \\
& \mathrm{O}_{9}-\mathrm{O}_{16}-\text { post-test after every unit }
\end{aligned}
$$

This study was conducted in the Cordillera Administrative Region (CAR). For content evaluation, twelve chemistry instructors in the region were involved. The twelve experts came from different state and private colleges and universities that are offering many different science-related courses with Inorganic Chemistry as part of their curriculum, namely: Benguet State University, Mountain Province State Polytechnic College, University of the Cordilleras and University of Baguio.

One hundred two (102) chemistry students of Mountain Province State Polytechnic College, Bontoc Campus enrolled in higher chemistry courses participated in the test for reliability of the resource package. The students were matched and paired up in terms of similarities in their mental ability that is, with the use of their final grades in inorganic chemistry. They were grouped into two with 51 students belonging to each of Groups A and B. For the try-out of the resource package, two inorganic chemistry classes of forty eight (48) students in each class participated in the study which lasted for five (5) months or 1 semester. Prior to the study, they were grouped into two as experimental and control groups.

For validity, the checklist used in the study was adopted from the General Criteria for Validating Instructional Materials by Rajeswari and Mohan (1995). This is a 12 -item scale with some modifications to fit the study. For reliability, a five-point scale checklist consisting of 24 items was used. It focused on the objectives, content and assessment for each chapter and the instructional characteristics of the resource package as a whole. The checklist with some modifications was 
patterned from an instrument used in a study by Caridaoan (2007). Both instruments asked the respondents to rate the degree to which they agree to certain specifications criteria.

To determine the performance of the students in inorganic chemistry on knowledge acquisition, pre-test and post-test questionnaires were used for every chapter.

\section{Method of Procedure}

There were four stages in the conduct of the study: Preparation Stage, Development Stage, Validation Stage and the Try-out Stage.

\section{Preparation Stage}

This stage started with the identification of local processes and community resources. A list of all local processes observable and all resources whether man-made or natural that are available in the community was made. Such a list was completed through personal observations of the researcher and through informal sharing and discussion with chemistry teachers and students.

Using the syllabus in inorganic chemistry, the local processes and community resources gathered were then studied vis-a-vis the different topics to determine appropriate subject matters in which they could be integrated. The syllabus was also updated to take account of the inclusion of local or community-based examples in appropriate topics. At this stage, a survey of literature was also conducted particularly on the guidelines on the format, technical details, techniques and modes of presentation of learning resource packages.

\section{Developmental Stage}

The resource package was prepared using the approved syllabus as basis. The selection of topics selected were based on concepts which are considered by students as difficult and those having local or community-based examples and/or applications as gathered during the informal sharing and discussion with other chemistry teachers in stage 1. Many reference materials in the form of books, journals, magazines and the internet were used in the preparation of the resource package. Such reference materials were properly cited in the reference section at the end of the resource package.

After preparing the resource package, this was shown to chemistry instructors in the college for critiquing. The corrections, suggestions and comments were then incorporated to improve the lessons in the resource package.

\section{Validation Stage}

For the content validation of the resource package, the researcher coordinated with 12 chemistry experts. The actual administration of the validation tool to the chemistry instructors was conducted following the policies of the institution where they belong. The evaluators were given two weeks at the least to appraise the contents of the resource package with the use of an evaluation checklist. The degree of validity of the contents of the resource package was determined after retrieval of all checklists.

The resource package was finally revised based on the pooled assessment of the instructor evaluators or experts. Their suggestions were considered for the improvement of the package.

For the reliability evaluation, the researcher personally distributed copies of the resource package to the students, oriented them on what the package contains, and guided them as they went over each chapter of the material. The student evaluators were given enough time to peruse the document and then were asked to evaluate the document through a questionnaire checklist.

\section{Try-out Stage}

Pilot testing of the validated resource package was conducted using quasi-experimental design. In this design, there is a control and an experimental group. The experimental treatment was given only to the experimental group who were then subjected to evaluation. This was followed by another unit then the second round of evaluation until all units contained in the resource package are taken up. A parallel schedule for the control group following this format was also done. The treatments used are as follows: 
handouts.

$\mathrm{T}_{0}-$ (control group). This class was taught with the use of the usual teacher-prepared

$\mathrm{T}_{1}$ - (experimental group). This class was taught with the use of the learning resource package as the major reference material in addition to the usual teacher-prepared handouts.

Before every unit, both control and experimental groups were pre-tested to find out how much they already know about the lessons. After each unit, a post-test was given to both classes. Pre-tests and post-tests were conducted on the same day for both the control and experimental group so as to avoid leakage of questions.

\section{Data Analysis}

To determine the degree of validity of contents of the instructional package, weighted mean was used. To determine the reliability of the resource package, the composite mean responses of each of the two groups of student evaluators for each part of the resource package were calculated. These were compared and the mean coefficient for correlation was calculated to determine the reliability of the resource package as a whole using the correlation of evaluation of parallel groups employing the Pearson Product-Moment Coefficient of Correlation or Pearson “r”. As stated by Key (1997), reliability is assessed based on the degree to which different judges agree in their assessment decisions. The t-test for independent samples was used to determine significant differences in the pre/post test scores of students in the control and experimental groups.

\section{Findings}

\section{Community-based Resources in the Learning Resource Package in Inorganic Chemistry}

A community-based LRP in inorganic chemistry was developed for this study. Such a package was made based on the updated syllabus for inorganic chemistry .The developed lessons were selected considering the possible integration of community resources and real life applications. From eight units in the syllabus, only seven units broken down into a total of twenty four lessons were selected for inclusion in the resource package. The whole unit on atomic structure and the lesson on chemical bonding were not included as part of the package as such topics are very much abstract, they deal with subatomic particles which cannot be concretized even with real life examples.

The material developed was designed to expose students to the world of chemistry as it applies to everyday life. Aside from commonly given examples, the material incorporates assets, materials, processes and practices that are accessible and noticeable in the community. These include natural resources such as the caves, waterfalls and hot springs; local products such as fruits, vegetables and indigenous food; local industries such as weaving, pottery, wine-making and smallscale mining; agricultural practices such as organic farming and everyday activities like cooking and washing.

\section{Reliability of the Resource Package}

Table 1 presents a summary of the data gathered on the agreement level of the perceptions of the two parallel groups of respondents on the reliability of the parts and instructional features of the community-based LRP in inorganic chemistry.

Table 1: Correlation of Reliability Evaluation of Students on the Community-based LRP in Inorganic Chemistry

\begin{tabular}{|c|c|c|c|c|}
\hline \multirow[t]{2}{*}{ SPECIFICATIONS CRITERIA } & \multicolumn{2}{|c|}{$\begin{array}{l}\text { GROUP } \\
\text { (X) }\end{array}$} & \multicolumn{2}{|c|}{$\begin{array}{l}\text { GROUP } \\
\text { (Y) }\end{array}$} \\
\hline & $\begin{array}{l}\text { Mean } \\
\mathrm{s}\end{array}$ & DE & Means & DE \\
\hline \multicolumn{5}{|c|}{ I. OBJECTIVES: The objectives of each chapter are } \\
\hline 1. specific & 4.64 & VMR & 4.60 & VMR \\
\hline 2. measurable & 4.37 & VMR & 4.40 & VMR \\
\hline 3. attainable & 4.54 & VMR & 4.51 & VMR \\
\hline 4. realistic & 4.76 & VMR & 4.67 & VMR \\
\hline 5. observable & 4.74 & VMR & 4.70 & VMR \\
\hline
\end{tabular}




\begin{tabular}{|c|c|c|c|c|}
\hline \multicolumn{5}{|l|}{ II. CONTENT: The lessons } \\
\hline 1. focus on specific skills and concepts. & 4.61 & VMR & 4.57 & VMR \\
\hline 2. suit the level of the learners. & 4.64 & VMR & 4.63 & VMR \\
\hline $\begin{array}{l}\text { 3. stimulate thinking and inquiry rather than mere rote } \\
\text { learning of facts. }\end{array}$ & 4.49 & VMR & 4.46 & VMR \\
\hline $\begin{array}{l}\text { 4. provide adequate community-based } \\
\text { examples to facilitate mastery of content and skills. }\end{array}$ & 4.80 & VMR & 4.73 & VMR \\
\hline $\begin{array}{l}\text { 5. spark the interest and reinforce the positive } \\
\text { attitudes of the students. }\end{array}$ & 4.50 & VMR & 4.60 & VMR \\
\hline $\begin{array}{l}\text { 6. help students to learn complex skills and concretize } \\
\text { concepts }\end{array}$ & 4.66 & VMR & 4.70 & VMR \\
\hline \multicolumn{5}{|l|}{ III. ASSESSMENT: The assessment activities } \\
\hline 1. relate to the concepts and topics & 4.64 & VMR & 4.70 & VMR \\
\hline 2. measu & 4.53 & VMR & 4.46 & MR \\
\hline 3. develop & 4.60 & VMR & 4.69 & MR \\
\hline 4. are consistent with the scope. & 4. & MR & 4.53 & MR \\
\hline \multicolumn{5}{|l|}{$\begin{array}{l}\text { IV. INSTRUCTIONAL CHARACTERISTICS: } \\
\text { The resource package }\end{array}$} \\
\hline $\begin{array}{l}\text { 1. Uses clear and easy to understand words, } \\
\text { phrases and sentences }\end{array}$ & 4.70 & VMR & 4.61 & VMR \\
\hline $\begin{array}{l}\text { 2. Contains instructions that are clearly and easily } \\
\text { understood by students }\end{array}$ & 4.74 & VMR & 4.69 & VMR \\
\hline $\begin{array}{l}\text { 3. Makes use of sentences that are appropriate in } \\
\text { length }\end{array}$ & 4.57 & VMR & 4.47 & VMR \\
\hline $\begin{array}{l}\text { 4. Makes use of a format students and teachers } \\
\text { can easily follow }\end{array}$ & 4.69 & VMR & 4.63 & VMR \\
\hline $\begin{array}{l}\text { 5. Makes use of appropriate community-based } \\
\text { examples and situations }\end{array}$ & 4.77 & VMR & 4.76 & VMR \\
\hline $\begin{array}{l}\text { 6. Encourages the use of low-cost and local } \\
\text { materials }\end{array}$ & 4.59 & VMR & 4.59 & VMR \\
\hline $\begin{array}{l}\text { 7. Uses words which are within the vocabulary of the } \\
\text { of the students }\end{array}$ & 4.53 & VMR & 4.51 & VMR \\
\hline $\begin{array}{l}\text { 8. Could help improve the performance of } \\
\text { students in Inorganic Chemistry }\end{array}$ & 4.84 & VMR & 4.79 & VMR \\
\hline $\begin{array}{l}\text { 9. Is useful to the students and teachers of } \\
\text { Inorganic Chemistry }\end{array}$ & 4.84 & VMR & 4.83 & VMR \\
\hline TOTAL & 111.23 & & 110.83 & \\
\hline Grand Mean & 4.62 & VMR & 4.63 & VMR \\
\hline
\end{tabular}

The table shows that the responses of the parallel groups of respondents have grand means both corresponding to Very Much Reliable with all specifications criteria having mean ratings corresponding also to Very Much Reliable. Statistical analysis using Pearson Product-Moment Correlation Coefficient revealed a computed coefficient of +0.8865 which is greater than the critical value of 0.404 at 0.05 level of significance and a degree of freedom of 22 . This means that there is a significant correlation of the evaluation ratings of the students on the characteristics of the different parts and the instructional characteristics of the resource package. It further means that both groups agree that the resource package is very much reliable as to its objectives, content, assessment and instructional characteristics.

\section{Validity of the Resource Package}

Table 2 presents a summary of the data gathered on the degree of validity of the contents of the community-based LRP in Inorganic Chemistry as evaluated by experts from the Cordillera Administrative Region.

The table indicates that over-all; the resource package developed is Very Much Valid in terms of its content as indicated by the grand mean of 4.49. Drawing from the definition of Jary \& Jary 
(1996), this means that the resource package is very much sound or true as far as can be judged by the expert evaluators.

Table 2: Content Validity of the Resource Package

\begin{tabular}{|c|c|c|}
\hline Specifications Criteria & WM & $\mathrm{DE}$ \\
\hline $\begin{array}{l}\text { 1. The contents of the resource package contribute to and accelerate } \\
\text { learning. }\end{array}$ & 4.67 & VMV \\
\hline $\begin{array}{l}\text { 2. The content presented by the resource package is sufficiently rich in } \\
\text { concepts and relationships. }\end{array}$ & 4.58 & VMV \\
\hline $\begin{array}{l}\text { 3. The resource package is adapted to the achievement of the desired } \\
\text { teaching objectives. }\end{array}$ & 4.58 & VMV \\
\hline $\begin{array}{l}\text { 4. The resource package provides accurate, up-to-date and relevant } \\
\text { information. }\end{array}$ & 4.33 & VMV \\
\hline $\begin{array}{l}\text { 5. The material is likely to call for vicarious experiencing, thinking, } \\
\text { reacting, discussing and studying. }\end{array}$ & 4.50 & VMV \\
\hline 6. The material is educationally sound. & 4.67 & VMV \\
\hline $\begin{array}{l}\text { 7. It stimulates thinking and inquiry rather than mere rote learning } \\
\text { of facts. }\end{array}$ & 4.33 & VMV \\
\hline $\begin{array}{l}\text { 8. It helps to reinforce the stimuli and positive attitude of the } \\
\text { students. }\end{array}$ & 4.25 & VMV \\
\hline $\begin{array}{l}\text { 9. It helps to create readiness and conscious attention among } \\
\text { learners. }\end{array}$ & 4.42 & VMV \\
\hline $\begin{array}{l}\text { 10. The material helps to guide thinking and evoking responses of } \\
\text { the learners. }\end{array}$ & 4.25 & VMV \\
\hline $\begin{array}{l}\text { 11. The material provides adequate local and community-based } \\
\text { examples to facilitate mastery of content and skills. }\end{array}$ & 4.92 & VMV \\
\hline $\begin{array}{l}\text { 12. The material aids to learn complex skills and concretize } \\
\text { concepts }\end{array}$ & 4.33 & VMV \\
\hline Grand Mean & 4.49 & VMV \\
\hline
\end{tabular}

Effects of the Learning Resource Package on Students' Performance in terms of Knowledge Acquisition

A t-test for independent samples was used to determine statistically significant differences in the mean scores of the two groups of respondents in terms of their pre-knowledge of the lessons to be tackled in each unit. The comparison of the means of the pre-test results of the students in the two groups is shown in Table 3 .

Table 3a: Comparison of Mean Pre-test Scores of the Students

\begin{tabular}{|c|c|c|c|c|c|c|}
\hline Groups & $\eta$ & $\bar{x}$ & Std. Dev. & Df & $\mathbf{t}$ & $\mathrm{p}$ \\
\hline Experimental 48 & 32.44 & 7.01 & & & & \\
\hline Control & 48 & 32.38 & 6.62 & & & \\
\hline
\end{tabular}

The pre-test scores of the two groups of students compared in Table $3 a$ using t-test for independent samples. The experimental groups' average pre-test score was $\bar{x}_{\text {experimental }}=32.44 \pm 7.01$; and that of the control group was $\overline{\mathrm{x}}_{\text {control }}=32.38 \pm 6.62$. Since $t_{(94)}=0.045<1.9855=t_{\text {crit }}$ (or p-value $=$ $.964>.05=a)$ these results show that there is no statistically significant difference between the mean pre-test scores of the two groups of students at 0.05 level. Prior to the introduction of a new unit, both groups have almost the same level of knowledge on the lessons of the next unit.

Post-tests were conducted every end of the unit. After the experimental period of five months (one semester), the post-tests were summed up to determine their mean post-test scores. The mean scores of the two groups of students in the post-tests are compared in Table $3 \mathrm{~b}$ using ttest for independent samples. 
Table 3.b. Comparison of Mean Post-test Scores of the Two Groups of Students

\begin{tabular}{|c|c|c|c|c|c|c|}
\hline Groups & & $\eta$ & $\bar{x}$ & Std. Dev. & Df & $\mathbf{t}$ \\
\hline Experim & 148 & 179.54 & 11.57 & \multirow{2}{*}{94} & \multirow{2}{*}{9.130 .000} & \\
\hline Control & 48 & 142.27 & 15.36 & & & \\
\hline
\end{tabular}

The mean post-test score for the experimental group was $\overline{\mathrm{x}}_{\text {experimental }}=179.54 \pm 11.57$; and that of the control group was $\overline{\mathrm{x}}_{\text {control }}=142.27 \pm 15.36$. Since $t_{(94)}=9.13>1.9855=t_{\text {crit }}$ (or p-value $=.000<$ $.05=a)$ these results indicate significant differences between the mean post-test scores of the students exposed to the learning resource package and those who were not. This further means that the post-test scores obtained by the students who used the learning resource package were significantly higher than that of the students who did not use the modules in class. The finding implies that the students who made use of the learning resource package in inorganic chemistry learned more and better as indicated by the higher mean post-test scores than those of the control group. This shows that the developed learning resource package enhanced students' performance in terms of knowledge acquisition. The results further imply that learning community resources and processes which were incorporated in the learning resource package could enhance student learning in inorganic chemistry.

\section{Conclusions and Implications}

Lessons in inorganic chemistry can be made more culturally-relevant and meaningful to the students through the identification and integration of community-based resources. Such community-based resources may take the form of natural resources, local products, everyday activities, agricultural practices and local industries. The student evaluators agree that the developed learning resource package is very much reliable as to objectives, lessons, assessments and instructional features. The chemistry experts involved in the study also regarded the contents of the community-based learning resource package as very much valid. When tested, the developed learning resource package enhanced students' performance in content-knowledge acquisition. Linking community-based resources to the lessons in chemistry indeed, makes learning more practical and relevant to learners' lives as it connects what they usually see in their surroundings to chemistry concepts.

\section{References}

Ahmad, J., Hassan, A., \& Abiddin, N. (2008). Developing Validity \& Reliability of a Drug Addiction Module Among Drug Addicts Who are Undergoing Treatment at Rehabilitation Centers. The Journal of International Social Research, 1(1).

Ballesteros, J. O. (2019). Localization \& Contextualization of Science Activities in Enhancing Learners' Performance. Retrieved on January 2019 from https://www.academia.edu/26424467/Localization_\&_Contextualization_of_Science_Activities_in_ Enhancing_Learners_Performance.

Belt, S. T., Leisvik, M. T. Hyde, A. J., \& Overton, T. L. (2005).Using a Context-based Approach to Undergraduate Chemistry Teacbing - A Case Study for Introductory Physical Chemistry. Chemistry Education Research \& Practice, The Royal Society of Chemistry.

Braund, M. R. (1999). Using Drama to Improve Student Teachers' Understeving in the Physical Sciences (Report). Brentton Hall College of the University of the Leeds. Retrieved July 6, 2011 from www.highbeam.com/doc/1G1-157586961.html.

Brown, T. L., LeMay, H. E., \& Bursten, B. E. (1999). Chemistry: The Central Science (8th Ed.). KY: Prentice Hall. Caridaoan, M. P. (2007). A Teaching Resource Package for Developing Science Process Skills in the Intermediate Grades. (Unpublished Master's Thesis), Mariano Marcos State University, Laoag City.

Centre for Teaching Excellence, University of Waterloo (CTE-UW). (2019). Community-Based Learning. Retrieved January 2019 from https:// uwaterloo.ca/centre-for-teaching-excellence.

Chemical Educational Foundation (CEF). (2014). You Be The Chemist Challenge: Passport to Science Exploration. Retrieved November 2014 from www.chemed.org.

De, C., \& Mary, J. T. (2006). Development \& Evaluation of Modules on Selected Topics in General Chemistry for Tertiary Students. (Unpublished Master's Thesis), Central Luzon State University.

De, S., \& Gregorio, M. (1999). A H\&book of Instructional Modules in General Inorganic Chemistry. University of Baguio, Baguio City. 
De, S., \& Gregorio, M. (2000). Common Statistical Tools \& Application Problems for Behavioral Sciences. MPSPC, Bontoc, Mountain Province.

Department of Education (Third Elementary Education Project, TEEP) \& UP College of Education. (2002). Culture Responsive Curriculum for Indigenous Peoples (CCIP).

Gabel, D. (1999). Enhancing the Conceptual Understeing of Science. Educational Horizons. H.W. Wilson Company.

Gabel, D. (1999). Improving Teaching \& Learning Through Chemistry Education Research: A look to the Future. Journal of Chemical Education. 4(1).

Hidden curriculum. (2014). In S. Abbott (Ed.), The glossary of education reform. Retrieved from http://edglossary.org/hidden-curriculum.

Jary, D., \& Jary, J. (1995). Sociology. Glasgow: Harper Collins.

Key, J. P. (1997). Research Design in Occupational Education. Excerpt from the Thesis H\&book. Oklahoma State University.

Magwilang, E. B. (2016). Teaching Chemistry in Context: Its Effects on Students' Motivation, Attitudes \& Achievement in Chemistry. International Journal of Teaching, Learning \& Educational Research, 15(4).

Ocampo, D. (2014). The K to 12 Curriculum. Retrieved from www.gov.ph/k-12.

Ornstein, A. (1990). The Development \& Evaluation of Curriculum Materials. National Association of Secondary School Principals.

Rajeswari, C., \& Mohan, S. (1995). Developing Multimedia Instructional Strategy Selection, Consolidation, Validation. Journal of Research in Educational Media, 3(1).

Soberano, A. (2009). Strategic Intervention Materials in Chemistry: Development \& Effectiveness. A Paper Presented in the $3^{\text {rd }}$ CosMED International Conference 2009, SEAMEO RECSAM.

University of the Philippines - National Institute for Science \& Mathematics Education Development (UPNISMED). (2003). Supervision of Science \& Mathematics Teaching, University of the Philippines.

\section{The Author}

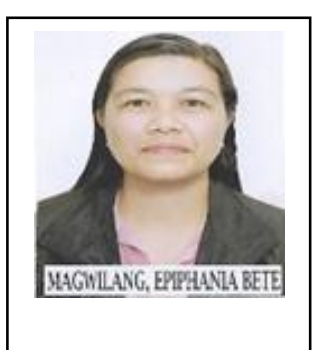

Epiphania B. Magwilang was born in Sagada, Mountain Province, Philippines on January 6, 1978. She finished Doctor of Education and Master of Arts in Education in Mountain Province State Polytechnic College, Bontoc Campus, Mountain Province and her Bachelor of Science in Chemical Engineering in St. Louis University, Baguio City. She is an associate professor at the Mountain Province State Polytechnic College, Bontoc Campus, Mountain Province. She has presented researches on local textile industries and chemistry teaching in various International Research Conferences held in the Philippines. Recently, she has copyrighted a book titled "A Community-based Learning Resource Package in Inorganic Chemistry" 